\title{
LA NATURALEZA CONSERVADORA DE LAS CONCEPCIONES ANTI-OCCIDENTALISTAS. OBSERVACIONES INCÓMODAS SOBRE UN TEMA ACTUAL
}

\author{
H. C. F. Mansilla \\ Academia de Ciencias de Bolivia
}

http://dx.doi.org/10.5209/rev_NOMA.2014.v42.n2.48778

\section{Aspectos preliminares}

En varios espacios del Tercer Mundo florece actualmente una amplia gama de estudios sobre la génesis y la situación contemporánea que aquellas regiones que se las considera las víctimas de la penetración capitalista y del imperialismo cultural de Occidente. Estos estudios se adhieren casi siempre a un horizonte normativo de carácter progresista o revolucionario, pero, al mismo tiempo, exhiben una marcada indiferencia hacia los principios críticos y emancipatorios del marxismo original. A menudo su base argumentativa está formada por una combinación de teorías postmodernistas, relativistas y deconstruccionistas, como es ahora lo usual en numerosas áreas del quehacer académico. Los enfoques más conocidos de estas corrientes son los llamados estudios subalternos y las teorías de la descolonización ${ }^{1}$.

Estas concepciones representan, en el fondo, una respuesta comprensible (dentro de un cierto contexto cultural) al impulso modernizador-globalizante de cuño mayoritariamente capitalista que de manera acelerada ha hecho su aparición en gran parte de Asia, África y América Latina desde la segunda mitad del siglo XX. Y esta respuesta - con muchas modificaciones y variantes - exhibe algunas de las características que a comienzos del siglo XIX tuvo la reacción romántica contra la Revolución Francesa y contra la transformación de las sociedades europeas en un orden signado por la vida urbana y la industrialización.

El propósito de este breve ensayo es indagar por la curiosa divulgación positiva que pensadores como Walter Benjamin (1892-1940) y Carl Schmitt (1888-1985)

\footnotetext{
1 Dentro de una notable cantidad de publicaciones cf. las obras fundamentales: Edward W. Said, Cultura e imperialismo, Barcelona: Anagrama 1996; Arif Dirlik, The Postcolonial Aura: Third World Criticism in the Age of Global Capitalism, Boulder: Westview Press 1997; Gayatri Chakravorty Spivak, Crítica de la razón poscolonial, Madrid: Akal 2010; Pablo Sandoval (comp.), Repensando la subalternidad. Miradas críticas desde / sobre América Latina, Lima: IEP 2009; Santiago Castro-Gómez / Ramón Grosfoguel (comps.), El giro decolonial: reflexiones para una diversidad epistémica más allá del capitalismo global, Bogotá: Siglo del Hombre Editores 2007, y en esta obra la breve introducción de los compiladores: Giro decolonial, teoría crítica y pensamiento heterárquico (pp. 9-23), donde se puede apreciar una buena información sobre la historia y las ramificaciones de esta tendencia teórica, pero también la fuerte inclinación autocelebratoria de sus autores y su argumentación básicamente circular, citándose sin cesar unos a otros.
} 
han alcanzado en América Latina entre los adherentes de las doctrinas de la subalternidad y la descolonización ${ }^{2}$. La crítica de esta popularidad nos puede conducir al fundamento conservador, antimodernista e irracionalista de estas concepciones, que es similar a la base teórica de los mencionados pensadores alemanes. En Alemania después de la Primera Guerra Mundial emergió un amplio rechazo contra las formas modernas de hacer política, rechazo que estaba inmerso en un romanticismo político como antítesis palpable de la llustración y el racionalismo. En amplios círculos intelectuales y políticos se expandió la concepción de que la fría razón occidental y la modernidad socio-política eran responsables por todos los males de la época. En ese contexto se rehabilitó la reputación positiva de los procesos decisorios basados en sentimientos profundos y se expandió la concepción de que la engorrosa democracia representativa pluralista configuraba el ámbito detestable de los mercaderes en ideas y programas. Según Jürgen Habermas, intelectuales como Martin Heidegger, Walter Benjamin y Carl Schmitt propagaron una respuesta pseudorrevolucionaria favorable a la vieja nostalgia por el antiguo orden - lo aparentemente Otro con respecto al racionalismo político -, y la respuesta habría sido reaccionaria ${ }^{3}$. En América Latina florece actualmente un fuerte descontento con la modernidad política de corte occidental. Esta genuina irritación colectiva está vinculada con un redescubrimiento de las culturas precolombinas y del catolicismo barroco ${ }^{4}$. Todo esto viene acompañado de una visión romántica y embellecida en torno a ambos fenómenos. Simultáneamente se puede detectar una tendencia vigorosa a postular un "marxismo latinoamericano heterodoxo", basado en Martin Heidegger, Walter Benjamin y Carl Schmitt, ampliado por los enfoques postmodernistas y los estudios postcoloniales y dulcificado por el psicoanálisis de Jacques Lacan.

En una buena parte de América Latina los procesos de modernización han destruido los vínculos primarios y las certezas doctrinarias de la población rural y las clases populares, y no han creado una esfera social que ofrezca las seguridades y certidumbres del mundo premoderno. Es comprensible, entonces, que surjan varios movimientos en contra de lo que se considera como lo negativo por excelencia: el cosmopolitismo liberal y pluralista y el egoísmo materialista decadente. Se trata, en líneas generales, de un anti-occidentalismo ${ }^{6}$ de

2 La preocupación por ambos autores sigue una línea apologética. Cf. Michael Löwy, Redención y utopía, Buenos Aires: Ed. El cielo por asalto 1997; Santiago C. Leiras, Los conceptos de política y decisionismo político en Carl Schmitt. Su repercusión en el debate latinoamericano, en: ECUADOR DEBATE (Quito), No 82, abril de 2011, pp. 159-174.

3 Jürgen Habermas, Eine Art Schadensabwicklung. Kleine politishe Schriften VI (Una forma de resarcimiento. Escritos políticos breves), Frankfurt: Suhrkamp 1987, pp. 103-109.

4 Cf. Bolívar Echeverría (comp.), Modernidad, mestizaje cultural y ethos barroco, México: UNAM / El equilibrista 1994; Bolívar Echeverría, La modernidad de lo barroco, México: Era 1998; Bolívar Echeverría, Vuelta de siglo, México: Era 2006.- Sobre el ethos barroco en cuanto ideología revolucionaria cf. Julio Peña y Lillo Echeverría, El ethos barroco como forma de resistencia al capitalismo, en: REVISTA SOCIALISTA (Buenos Aires), No 8, invierno de 2013.

Martín Cortés, Entre Benjamin y Schmitt: el rompecabezas de José Aricó para pensar América Latina, en: NÓMADAS. REVISTA CRÍTICA DE CIENCIAS SOCIALES Y JURÍDICAS (Madrid), número especial dedicado a América Latina dentro del vol. 2011 (www.ucm.es/info/nomadas/MT_americalatina/martincortes.pdf) [11.12.2013].

Ian Buruma / Avishai Margalit, Occidentalism. The West in the Eyes of Its Enemies, New York: Penguin Press 2004. 
inclinaciones ruralistas, partidario de revitalizar las costumbres y los credos ancestrales, un movimiento de amplio alcance social, que ahora adquiere una dirección anti-imperialista y, simultáneamente, un tinte paternalista, favorable al autoritarismo caudillista de las tradiciones populistas. Esta amalgama de orientaciones y resultados no es sorpresiva. En amplias porciones de América Latina y en el ámbito islámico la civilización occidental es percibida como una tendencia decadente, superficial, materialista, sin raíces y sin sueños, que habría destruido las antiguas culturas previas al contacto con Europa y que hoy haría peligrar el humanismo espontáneo de las clases populares. A la modernidad occidental le faltaría una gran visión histórica y religiosa, que vaya más allá de los mezquinos afanes cotidianos ${ }^{7}$.

En el mundo andino, por ejemplo, la moderna democracia pluralista es considerada por sus detractores como un orden social débil y sin sustancia, antiheroico, mediocre y corrupto. En la consciencia anti-occidentalista ${ }^{8}$, la democracia moderna es vista como el espacio de los comerciantes y administradores y como un mero sistema competitivo, en el cual los partidos luchan abiertamente por el poder y donde la resolución de conflictos se produce mediante negociaciones y compromisos aleatorios. Es decir: este tipo de democracia sería el ámbito donde escasean los designios eminentes y los propósitos sublimes. Este orden político sería un invento artificial y artificioso proveniente de la dimensión urbana, de antigüedad y respetabilidad muy discutibles, creada por mercaderes, que habrían trasladado el sistema competitivo cortoplacista propio del mercado al terreno político, es decir al campo de los sentimientos nobles, las intenciones prístinas y los asuntos de largo aliento. El pluralismo ideológico, el parlamento como lugar de negociación de intereses, los partidos contendientes entre sí y los debates interminables en el seno de la opinión pública son entendidos como obstáculos a un desarrollo auténtico, como una rémora frente a las apremiantes necesidades del momento y como una pérdida de tiempo en comparación con el presunto mejor desempeño de un gobierno fuerte y de un líder enérgico. Se repite la crítica, muy difundida, acerca de las debilidades innatas y las complicaciones innecesarias del orden liberal-democrático.

La modernización y la globalización han generado un amplio repudio de las formas relativamente abstractas de hacer política, lo que es, en el fondo, un comprensible rechazo del mundo moderno, percibido como insoportablemente complejo e insolidario. El resultado teórico de todo esto es una ideología compensatoria con una clara inclinación armonicista ${ }^{9}$. Esta opción teórica se nutre de dos procedimientos fundamentales enlazados entre sí:

\footnotetext{
7 Cf. Ulrich Mücke, Gegen Aufklärung und Revolution. Die Entstehung konservativen Denkens in der iberischen Welt (1770-1840) (Contra la Ilustración y la revolución. La formación del pensamiento conservador en el mundo ibérico [1770-1840]), Colonia: Böhlau 2008.

8 Cf. uno de los testimonios más elocuentes del indianismo radical, cuyas conclusiones son previsibles. El "retorno a la verdadera patria", al "paradigma de la vida", es la restauración del modelo civilizatorio prehispánico: Iván Apaza Calle, Colonialismo y contribución en el indianismo, El Alto: Pachakuti / Awqa 2011, pp. 70-76, 87-90, 119.

9 Cf. la crítica al indigenismo y al indianismo desde posiciones marxistas autoctonistas: Jorge Luis Soza Soruco, El discurso de la "cosmovisión andina". Una lectura marxista del mundo andino, La Paz: EI Viejo Topo 2012, especialmente pp. I-IV, 87, 117.
} 
(a) Una simplificación cognoscitiva, que tiende a percibir la realidad sociohistórica mediante oposiciones binarias excluyentes (enfoque teórico expuesto temprana y brillantemente por Walter Benjamin); y

(b) una simplificación decisoria, que favorece tomas de posición sólo entre dos posibilidades definidas arbitrariamente (doctrina unida a la obra de Carl Schmitt).

\section{La popularidad de las oposiciones binarias de carácter maniqueísta y las propensiones arcaizantes de las teorías de la descolonización}

Las teorías de la subalternidad y la descolonización corresponden a una sensibilidad proclive a una visión rudimentaria de la esfera social: se percibe la realidad del mundo circundante mediante oposiciones binarias, como ser: lo propio / lo ajeno; amigos / enemigos; la verdad / la mentira; lo familiar / lo extraño. Estas han sido usuales en numerosos modelos civilizatorios, sobre todo en las etapas iniciales del desarrollo histórico. Sirven evidentemente para una primera orientación en un campo que a menudo es hostil; generan además un sentimiento de seguridad y pertenencia. Si bien su utilidad es aceptable en ordenamientos sociales relativamente poco evolucionados, su pervivencia en sociedades muy complejas, como son las latinoamericanas del siglo XXI, produce simplificaciones cognoscitivas y conlleva asimismo una consolidación de estructuras mentales y valores de orientación con un claro matiz arcaico, paternalista y autoritario. No se discute aquí la relevancia de ciertos elementos altamente positivos que a menudo están vinculados con ese mundo premoderno - como la existencia de redes de solidaridad inmediata y la vigencia de creencias que otorgan un sentido pleno a la vida humana y a las identidades colectivas e individuales -, pero hay que considerar la posibilidad de que hoy el pensar en oposiciones binarias conduce a la incomprensión de la diferenciación social y cultural alcanzada entre tanto en América Latina y prepara de manera indirecta el terreno ideológico para el advenimiento de regímenes autoritarios. En el imaginario popular las contraposiciones simples son vistas como un instrumento adecuado para enfrentarse a la complejidad y a la insolidaridad crecientes del ámbito moderno, pero los efectos socio-culturales de esta acción arcaizante son el desconocimiento de la dimensión global en el largo plazo y la preservación del infantilismo político convencional ${ }^{10}$.

Las oposiciones binarias excluyentes se manifiestan dramáticamente en las aseveraciones del pensador mexicano Guillermo Bonfil Batalla, el representante más destacado del indianismo contemporáneo: "La solidaridad, el respeto, la honradez, la sobriedad y el amor" constituirían los "valores centrales, piedras fundadoras de la civilización india", mientras que las normativas de la civilización occidental son descritas como "egoísmo, engaño, desengaño, apetito insaciable de bienes materiales, odio; todo lo cual prueba la historia y lo comprueba la observación diaria de la vida urbana, reducto y fortaleza de la invasión

10 Sobre este punto específico cf. la interesante obra de un autor cercano a los experimentos populistas de la actualidad: Pablo Stefanoni, "Qué hacer con los indios...". Y otros traumas irresueltos de la colonialidad, La Paz: Plural 2010, pp. 36-40. 
occidental"11. Y continúa el mismo autor: "La miseria, el hambre, la enfermedad y las conductas antisociales" no serían herencia de la civilización india, "sino productos directos de la dominación". Formarían parte de una circunstancia temporal [la invasión occidental], pero no representarían "los rasgos constitutivos de la civilización india"12.

Esta concepción, muy popular en varios ámbitos culturales latinoamericanos, incluyendo, en primer lugar, el campo universitario (donde florecen las teorías de la subalternidad y la descolonización ${ }^{13}$ ), conlleva el rechazo del Otro en nombre de un anticolonialismo ruralista que coloca al campesinado de origen indígena en el centro de la historia como sujeto privilegiado de los decursos evolutivos. Esta contraposición binaria de dos sistemas civilizatorios y el desdén concomitante por la democracia contienen elementos premodernos y hasta pre-urbanos, lo que es paradójicamente un indicio de su origen académico e intelectual. Por lo demás se puede constatar fácilmente que esta contraposición maniqueísta de valores enteramente positivos de un lado y profundamente negativos del otro tuvo y tiene poco que ver con la realidad de cualquier sociedad, como la oposición binaria radical entre el mundo luminoso y puro del campo y el terreno sórdido y pecaminoso de la ciudad ${ }^{14}$. Similar es el temprano testimonio del más ilustre crítico literario boliviano del siglo XX, Carlos Medinaceli: "Lo corrompido en nuestro país, y más que corrompido, artificioso y falso, son las ciudades y la vida de ciudad" "15. Y prosiguió: "Lo verdadero y sano es el campo, y son las campesinas costumbres [...]. Éramos un pueblo sano, de costumbres y vida aldeanas y feudales [...]"16. Su descripción de lo negativo no deja lugar a dudas: "La libertad y la democracia son, precisamente, dos síntomas de decadencia, de corrupción racial, social y política"17.

Se proclama simultáneamente la superioridad ética del indio y la inferioridad moral del europeo, con lo cual, además, se relativizan los logros culturales de Occidente: estos se hallarían exclusivamente en el terreno técnico-material, pero ya "contaminados" por la racionalidad instrumental y el principio de eficacia ${ }^{18}$. Usando una contraposición binaria excluyente, el presidente argentino Juan Domingo Perón postuló la existencia de dos líneas en la cultura política de su

11 Guillermo Bonfil Batalla, Aculturación e indigenismo: la respuesta india, en: José Alcina Franch (comp.), Indianismo e indigenismo en América, Madrid: Alianza 1990, pp. 189-209, aquí p. 197.

12 Ibid., p. 199.

13 Cf. entre otros: Jorge Viaña et al., Interculturalidad crítica y descolonización. Fundamentos para el debate, La Paz: Instituto Internacional de Integración del Convenio Andrés Bello 2011; Catherine Walsh (comp.), Pensamiento crítico y matriz (de)colonial. Reflexiones latinoamericanas, Quito: UASB / Abya Yala 2005; Raúl Fornet-Betancourt (comp.), Culturas y poder. Interacción y asimetría entre las culturas en el contexto de la globalización, Bilbao: Desclée de Brouwer 2003.

14 Guillermo Bonfil Batalla, op. cit. (nota 11), p. 196.

15 Carlos Medinaceli, Carta a José Enrique Viaña (Valle de San Pedro, 12 de abril de 1928), en: Mariano Baptista Gumucio (comp.), Cartas para comprender la historia de Bolivia, Oruro: ZOFRO 2013, pp. 364-371, aquí p. 366.

16 Ibid., p. 366.

17 Ibid.

18 Guillermo Bonfil Batalla, op. cit. (nota 11), p. 197. Cf. también: Guillermo Bonfil Batalla, Utopía y revolución. El pensamiento político contemporáneo de los indios en América Latina, México: Nueva Imagen 1981; Guillermo Bonfil Batalla, México profundo: una civilización negada, México: Grijalbo 1990. 
país: una nacional, partidaria de la civilización hispano-católica, fuerte en las provincias y representada por los caudillos locales; la otra antinacional y anglosajona, afincada en Buenos Aires, personificada por la aristocracia europeizante, los masones y los partidos liberales ${ }^{19}$. Las reminiscencias del catolicismo barroco en el lenguaje del nacionalismo del siglo XX son evidentes.

Este dualismo maniqueísta y su correlato ético-social pertenecen al núcleo del pensar y sentir de muchas comunidades rurales latinoamericanas y asimismo de ambientes citadinos de urbanización acelerada y superficial. Aunque se hallan en cierto proceso de declinación, todavía manifiestan una visión del mundo compartida por amplios segmentos poblacionales. En el terreno de la religiosidad popular esta doctrina presupone una esencia identificatoria constituida por el catolicismo ibérico tradicional, el ritualismo y el comunitarismo de las religiones precolombinas, el barroco en cuanto forma original de síntesis cultural y los modelos de convivencia de las clases populares, presuntamente incontaminadas por la perniciosa civilización occidental moderna. Esta concepción representa probablemente (a) la nostalgia de sus autores por sistemas ideales de solidaridad humana que nunca han existido, (b) su animadversión por la compleja modernidad contemporánea y (c) una curiosa simpatía, típica de sofisticados intelectuales citadinos, por los resabios populares y autoritarios del orden premoderno y rural, es decir por una porción de la tradicionalidad poco digna de ser recuperada.

El término maniqueísmo es empleado aquí exclusivamente en sentido político y cultural, para denotar una constelación donde se sedimentan ante todo dos corrientes opuestas - que pueden ser movimientos políticos o tendencias de pensamiento -, con exclusión de otras alternativas Estas corrientes se hallan sumidas en una pugna permanente, condenadas a eliminarse la una a la otra. La idea rectora del maniqueísmo es muy simple: "Quien no está conmigo, está contra mí". Lo más significativo del maniqueísmo político-ideológico reside en el principio siguiente. La estrategia política más conveniente no es impulsar una programática propia, clara y distinta, sino tratar de suprimir o, por lo menos, debilitar al adversario, con lo que ya se habría avanzado considerablemente en la consecución de los fines propios ${ }^{20}$.

Principios y motivos maniqueístas se hallan en todas las culturas y todos los tiempos, pese a la diferenciación creciente de la vida social y de las actividades intelectuales. Ahora bien: amplias capas sociales con un grado relativamente modesto de instrucción y con esperanzas fácilmente definibles favorecen este pensar y sentir en dualidades mutuamente excluyentes. A ello se debe, por ejemplo, la gran popularidad de referéndums y otros tipos de consulta plebiscitaria, en los cuales se expresa la necesidad de descartar la opción adversaria de un modo fácilmente comprensible. Los desarreglos económicos y la atmósfera de una dilatada inseguridad que engendraron los regímenes neoliberales en América Latina a fines del siglo XX han preparado el terreno para la propagación (o el renacimiento) del maniqueísmo político, cuya popularidad en

19 Juan Domingo Perón, La hora de los pueblos, Buenos Aires: Pleamar 1973, pp. 11-12.

20 Esta propensión maniqueísta está también contenida en la concepción político-práctica de Carl Schmitt. Cf. el excelente ensayo (pese a su modesto título) de Reinhard Mehring, Carl Schmitt zur Einführung (Introducción a Carl Schmitt), Hamburgo: Junius 2001, p. 41. 
América Latina no ha disminuido sustancialmente, pese a los intensos procesos de modernización. En las primeras décadas del siglo XXI, algunos presupuestos histórico-filosóficos de vieja data, que provienen del acervo del catolicismo barroco y popular, han sido revigorizados por pensadores y literatos adscritos a las diferentes versiones del indigenismo e indianismo y a las teorías de la descolonización.

Desde la época colonial hasta el presente, la religiosidad y la mentalidad populares tienden a constituirse y a expresarse en dualismos fácilmente comprensibles: la fe verdadera de los creyentes frente a la razón deleznable de los filósofos, la sana ortodoxia doctrinaria contra las peligrosas herejías, la cultura ibero-católica frente a los modelos civilizatorios importados de los ámbitos francés y anglosajón, y las costumbres propias, enraizadas en una venerable tradición, contra las novedades y frivolidades procedentes de la modernidad occidental. En el terreno político, este modo dicotómico de percibir la realidad se traduce en una contraposición elemental (amigos vs. enemigos; ideales vs. intereses), que dificulta la aceptación del pluralismo de ideas y partidos y la tolerancia con respecto a los adversarios. Lo positivo es visto en la unidad doctrinaria, la disciplina jerárquica de la Iglesia (o el partido), el sueño de hogar y fraternidad y la ilusión de la solidaridad practicada, mientras que lo negativo se hallaría en la diversidad de opiniones y valores de orientación, en la dilución de la autoridad paternal y en la frialdad y el egoísmo de las relaciones humanas que prevalecen en el moderno mundo capitalista.

El elemento central de esta construcción teórica es una contraposición artificial de dos culturas, la occidental-capitalista y la indígena-comunitaria. Se trata un genuino maniqueísmo fundamentalista que induce a un rigorismo moral-político que tiene poco que ver con los problemas cotidianos de las sociedades latinoamericanas, las que poseen identidades múltiples y cambiantes y relaciones complejas con el mundo occidental. Pero este dualismo maniqueísta pertenece al núcleo del pensar y sentir de muchas comunidades rurales latinoamericanas, y manifiesta una visión del mundo compartida por movimientos intelectuales y políticos de evidente fuerza de convocatoria. Según Rodolfo Kusch, cuya obra sirve de cimiento conceptual a las teorías de la descolonización, el núcleo de la genuina identidad latinoamericana estaría constituido por el ritualismo y el comunitarismo de las religiones precolombinas, el catolicismo ibérico tradicional, el barroco en cuanto forma original de síntesis cultural y los modelos de convivencia de las clases populares, presuntamente incontaminadas por la perniciosa civilización occidental moderna. El punto más divulgado y aceptado de esta doctrina es la contraposición entre dos culturas en el mismo suelo latinoamericano: una superficial y vistosa, demoníaca y mundana, inauténtica y elitaria, producto de la civilización decadente de Europa, y otra cultura profunda y medio oculta, de origen indígena, pero que viene de abajo y está apegada a la tierra y comprometida con el aquí y el ahora ${ }^{21}$. Esta última cultura es la que representa la "alternativa real", pues su "metafísica alteridad" garantizaría su cualidad como "lo Otro" con respecto al ámbito moderno y capitalista ${ }^{22}$.

En una de las obras teóricamente más exigentes del contexto de la descolonización, Javier Sanjinés postula francamente la fidelidad a un orden

21 Rudolfo Kusch, América profunda, Buenos Aires: Bonum 1975, pp. 89-92, 124-127.

22 Enrique Dussel, Filosofía de la liberación, Bogotá: Universidad Santo Tomás 1980, p. 90. 
social arcaico - porque sería profundo y en armonía con la naturaleza -, en detrimento del orden moderno urbano, que sería una fuente artificial de corrupción y decadencia. "Lo arcaico", dice este autor, "no es lo caído en desuso, sino lo profundo" ${ }^{23}$. Sanjinés da a entender que los fenómenos modernos, como la formación de la nación cívica mediante la decisión consciente de los ciudadanos, representan algo superficial que no alcanza la dignidad ontológica de lo arcaico, de las estructuras comunitarias precoloniales y del modelo endógenoindígena ${ }^{24}$. La democracia en cuanto deliberación racional y abierta constituiría un factor exógeno y moderno, por lo tanto: deleznable, insustancial y hasta frívolo. No tendría la calidad y la solidez de los valores de la tradición, que son la "promesa de la continuidad": "la fidelidad, la admiración y la gratitud"25. Sólo ellos evitarían "esa multiplicidad confusa de tendencias y aspiraciones que supone el libre albedrío individualista. Se trata, pues de la fidelidad a una causa superior que supera las mudanzas del tiempo"26. El libro de Sanjinés - abstracto y académico como pocos - resulta ser un auténtico Manifiesto conservador, aunque se enmarca en una intención política radical. El autor no quiere analizar ni criticar, sino admirar y agradecer una herencia cultural que viene de muy atrás. Hay que acercarse a ella únicamente con amor y lealtad. Es, en cierto sentido, un retorno a posiciones anteriores a todo racionalismo, una regresión a una constelación signada por una teología elemental de unas pocas creencias sólidas e inamovibles, y un claro rechazo de la pluralidad ideológica y del individualismo liberal que caracterizan a nuestra era.

\section{Las dos esferas del maniqueísmo cultural}

Para esclarecer esta temática se acude aquí a una crítica de las concepciones de Walter Benjamin a causa de la calidad de su obra y, ante todo, por haber formulado temprana y lúcidamente una concepción sobre las antinomias binarias de la cultura y de la política que es muy semejante a la que prevalece en dilatados sectores latinoamericanos. Por otra parte, el alto nivel de abstracción de estos esfuerzos teóricos nos permite reconocer aspectos similares en aportes intelectuales de diversas épocas y regiones.

En el núcleo del pensamiento benjaminiano y en teorías afines se encuentra la contraposición de dos grandes fuerzas. Por un lado se halla la esfera del sentimiento religioso, de los sueños y anhelos de la sociedad y de las concepciones morales de la misma, esfera que se acerca al campo de lo divino y que por ello no puede ser comprendida - o descrita - adecuadamente sólo mediante esfuerzos racionales. Es el espacio del amor, el altruismo, la confianza y la espontaneidad en las relaciones humanas, el terreno de la solidaridad inmediata entre los hombres y de la amistad sin cálculo de intereses, pero también el lugar de las utopías sociales, la cólera revolucionaria y la violencia política ante las injusticias históricas. Aquí no tienen cabida las intermediaciones institucionales, las limitaciones impuestas por leyes y estatutos. Esta esfera posee una dignidad ontológica superior en comparación con las otras actividades y creaciones humanas. A ella no se puede aplicar una reflexión que analice la

23 Javier Sanjinés C., Rescoldos del pasado. Conflictos culturales en sociedades postcoloniales, La Paz: PIEB / Plural 2009, p. 191.

24 Ibid., pp. 168-169.

25 Ibid., p. 12.

26 Ibid. 
proporcionalidad de los medios (por ejemplo: políticos o institucionales) o la adecuación instrumental de medidas con respecto a fines, pues estos últimos estarían más allá de todo esquema analítico-racionalista. Los valores de orientación de esta esfera son "puros", en el sentido de que su vigencia no depende de mediaciones, las que siempre traen consigo un factor de distorsión y engaño, una posibilidad de falseamiento y ventajismo. De acuerdo a esta reflexión, la violencia revolucionaria tiene ese carácter de pureza y no puede ser juzgada por el mezquino cálculo de proporciones. Las revoluciones genuinas, por lo tanto, tendrían un derecho histórico superior frente a toda crítica proveniente del liberalismo racionalista ${ }^{27}$.

La otra esfera, basada en el principio de rendimiento y eficacia, está constituida por los asuntos prosaicos de la vida ordinaria: el campo laboral, los negocios y la política convencional. (Es decir: la política como se presenta rutinariamente, no la política en cuanto conquista sublime de la emancipación humana.) Aquí prevalecen la racionalidad instrumental y la proporcionalidad de los medios. Es el campo de las instituciones, los estatutos y las leyes, pero también de los intereses particulares. La racionalidad instrumental permea todos los aspectos de este espacio, el que puede ser descrito como la evitación o mitigación de conflictos a través de mecanismos institucionalizados como el derecho positivo y los contratos. Constituye el plano del egoísmo y de los cálculos mezquinos; es también el terreno por excelencia de las intermediaciones, cuyos instrumentos son las negociaciones políticas, los compromisos y los acuerdos provisionales ${ }^{28}$.

Para Walter Benjamin y, en general, para los autores de las teorías aquí mencionadas, hay que atribuir a la primera esfera - la de la religión, la moralidad y el altruismo - una dignidad superior por encima del campo de la institucionalidad y las intermediaciones. Este último terreno concita casi siempre un marcado sentimiento de desconfianza y desprecio, pues es considerado como el lugar privilegiado de las patologías sociales. Se supone que los factores asociados a la primera esfera disfrutan de las cualidades de pureza, autorreferencialidad $y$ hasta sacralidad. Estos aspectos no están, afortunadamente, sometidos al principio de rendimiento, eficacia y proporcionalidad; no prevalecen allí ni la racionalidad instrumental ni el detestable debate de intereses. Aquí se encuentra, en cambio, el potencial de nuevas concepciones, obviamente revolucionarias, acerca de la moral y la política ${ }^{29}$.

\footnotetext{
27 Walter Benjamin, Zur Kritik der Gewalt (Sobre la crítica de la violencia) [1920-1921], en: Benjamin, Zur Kritik der Gewalt und andere Aufsätze (Sobre la crítica de la violencia y otros ensayos), Frankfurt: Suhrkamp 1965, pp. 29-65.- Acerca de la relevancia del pensamiento benjaminiano para América Latina cf. el número monográfico de REVISTA DE CIENCIAS SOCIALES (San José / Costa Rica), № 100, abril-junio de 2003, dedicado al tema: "Homenaje a Walter Benjamin, pilar del pensamiento crítico", particularmente: Héctor González Morera, Reflexiones sobre Walter Benjamin: aproximación a la experiencia para abordar otras formas de conocimiento, en: ibid., pp. 31-47; Mauricio Frajman Lerner, El mesianismo en el pensamiento de Walter Benjamin, en: ibid., pp. 71-76.

${ }_{28}$ Walter Benjamin, op. cit. (nota 27), pp. 58-63.

29 Dentro de esta corriente cf. Giorgio Agamben, Homo sacer. Die souveräne Macht und das nackte Leben (Homo sacer. El poder soberano y la vida desnuda), Frankfurt: Suhrkamp 2002, passim; una posición similar: Herbert Marcuse, Revolution und Kritik der Gewalt (Revolución y crítica de la violencia), en: Peter Bulthaup (comp.), Materialien zu Benjamins Thesen "Über den Begriff der Geschichte" (Materiales en torno a las tesis de Benjamin "Sobre el concepto de historia"), Frankfurt: Suhrkamp 1965, pp. 23-27.
} 
En esta línea, y apoyado en Georges Sorel, Walter Benjamin aseveró que la violencia revolucionaria y utópica es pura y autorreferencial: un fin en sí misma ${ }^{30}$. De acuerdo a Benjamin, la violencia revolucionaria y utópica no puede ser juzgada desde la perspectiva de la proporcionalidad de los medios, ni desde la óptica convencional de la filosofía de la historia, ni, menos aun, desde un punto de vista jurídico convencional. Al ser una meta por derecho propio, la violencia revolucionaria se convierte en sagrada. Igual que Sorel, Benjamin experimentó un notable entusiasmo por la "heroica energía de las masas" ${ }^{31}$. Como dice Axel Honneth en un estimulante ensayo, el propósito de Sorel y Benjamin consistía en mantener el concepto de lo político en la lejanía más grande posible de la pugna de intereses, en un "anti-utilitarismo" doctrinario ${ }^{32}$. Este intento de concebir la "genuina" política - aquella que se consagra exclusivamente a la consecución de la emancipación humana - en un estado de pureza prístina no hace justicia ni a la realidad histórica ni al núcleo de la política, que es la perenne discusión de intereses en el espacio de lo contingente y aleatorio y no algo eximido de metas y anhelos cotidianos y prosaicos, es decir eminentemente humanos.

La sacralización de la violencia física inmediata - en medio de un contexto claramente maniqueísta - fue postulada también por Frantz Fanon, cuya obra ha tenido una recepción muy positiva en los cenáculos académicos latinoamericanos dedicados a los estudios postcoloniales y subalternos. La violencia es enaltecida como la reintegración del individuo al todo social que le brinda sentido, como la recuperación de la transparencia perdida y como manifestación de la "praxis absoluta". "La violencia unifica al pueblo"33 y es la "humanidad" del revolucionario. Fanon contrapone la sublevación contra el poder colonial y su "hombre total" frente a la Europa decadente, criminal y corrupta; sólo la revolución cruenta convertiría al habitante del Tercer Mundo en un ser humano, únicamente la lucha armada constituiría el camino de la liberación social y el mecanismo del progreso histórico ${ }^{34}$.

El resultado del esfuerzo teórico de Walter Benjamin y de pensadores similares puede ser visto como un relleno quiliástico del concepto marxista de revolución. Así la política adquiriría definitivamente la calidad de un fin religioso en sí mismo. Al mismo tiempo se puede afirmar que estas posiciones son básicamente conservadoras 0 , mejor dicho, tradicionalistas, porque regresan acríticamente a una posición anterior a la llustración y al racionalismo y hasta previa a los debates de los estoicos en la Antigüedad clásica y a todo esfuerzo para transformar la política en algo previsible y racional-argumentativo o, por lo menos, exento de las arbitrariedades más inhumanas. Al sacralizar la política de la manera señalada,

\footnotetext{
30 Walter Benjamin, op. cit. (nota 27), p. 52.- Para una visión diferente de esta problemática cf. el brillante ensayo de Isaiah Berlin, Georges Sorel, en: Isaiah Berlin, Against the Current. Essays in the History of Ideas, Londres: Hogarth 1980, pp. 296-332.

Axel Honneth, Eine geschichtsphilosophische Rettung des Sakralen. Zu Benjamis "Kritik der Gewalt" (Un rescate histórico-filosófico de lo sagrado. En torno a la "Crítica de la violencia" de Benjamin), en: Axel Honneth, Pathologien der Vernunft. Geschichte und Gegenwart der Kritischen Theorie (Patologías de la razón. Historia y presente de la Teoría Crítica), Frankfurt: Suhrkamp 2007, pp. 112-156, aquí p. 115.

32 Ibid., p. 116.- Sobre la necesidad de rechazar la política como el campo de los compromisos y los pactos cf. Walter Benjamin, op. cit. (nota 27), pp. 46-47.

33 Frantz Fanon, Los condenados de la tierra, México: FCE 1963, p. 20, 22, 32, 77, 86.

34 Ibid., pp. 291-292.
} 
Benjamin y pensadores afines devaluaron las normativas filosóficas y jurídicas que tratan de proteger la dignidad humana de las incursiones de violencias y poderes irracionales, a las cuales pertenecen, por ejemplo, la separación entre las esferas púbica y privada, la clara distinción entre Estado y praxis religiosa y la vigencia irrestricta de los derechos humanos. En este contexto es donde ocurre la negación de la legitimidad de la modernidad: esta habría sido no sólo casual y contingente, sino también trivial y vana. $Y$ de acuerdo a esto último también se puede y se debe relativizar la significación de todos los grandes logros de la cultura occidental y del racionalismo con la consciencia tranquila y, al mismo tiempo, se proclama la necesidad de revigorizar elementos del orden premoderno como el decisionismo político, la vigencia de caudillos tradicionales, el retorno de las jerarquías sociales convencionales y los modelos rutinarios de autoritarismo y populismo.

Sólo desde una posición premoderna y prerracional se puede afirmar que la democracia representativa pluralista es antiheroica, insustancial, trivial e inmoral y que no tiene valor porque habría sido creada por espíritus prosaicos, como mercaderes y funcionarios. Únicamente desde una perspectiva axiológica absolutista - como la de Walter Benjamin - se podría esperar un método perfecto para regir los asuntos humanos, que brinde además una completa identificación entre gobernantes y gobernados. De acuerdo a la amplia experiencia histórica, tenemos que contentarnos con el mal menor y con soluciones provisionales, que no por esto merecen ser vistas como la banalización de los asuntos públicos. La impugnación de la moderna democracia liberal representativa, con sus complicados mecanismos de controles y contrapesos, trajo consigo automáticamente una revalorización positiva de formas elementales y hasta arcaicas de "hacer política": la democracia directa, el referéndum y el plebiscito, la movilización de masas en pos de cuestiones fácilmente comprensibles, el entusiasmo de las emociones "puras" (es decir: sencillas, nobles, profundamente sentidas) y su corolario inevitable, la vigencia de los caudillos. Benjamin sostuvo en el mismo contexto que el "dogma de la santidad de la vida" sería una de las últimas confusiones de la "debilitada tradición occidental"35. No es entonces de extrañar que compartía muchas de estas ideas con Carl Schmitt, el jurista más importante del nacionalsocialismo alemán, cuya influencia no deja de crecer en círculos "progresistas" y populistas de América Latina. Como afirma Honneth en forma global acerca de la teoría de Benjamin: su concepción del derecho tenía tintes terroristas, su ideal acerca de la violencia parecía teocrático y su imagen de la revolución era quiliástico-mesiánica ${ }^{36}$.

\section{La significación del decisionismo en la actualidad}

La desilusión que ha significado el periodo neoliberal en América Latina (alrededor de 1980 a 2000) ha conllevado una dilatada opinión muy crítica con la democracia representativa pluralista. Este amplio desencanto se combina con la creencia popular de que los complicados mecanismos y procedimientos de la

\footnotetext{
$35 \quad$ Walter Benjamin, op. cit. (nota 27), p. 63.- Sobre Benjamin cf. Jürgen Habermas, Bewusstmachende oder rettende Kritik. Die Aktualität Walter Benjamins (La critica de hace consciente o que salva. La actualidad de Walter Benjamin), in: Jürgen Habermas, Politik, Kunst, Religion. Essays über zeitgenössische Philosophen (Política, arte, religión. Ensayos en torno a filósofos contemporáneos), Stuttgart: Reclam 1978, pp. 48-95.

36 Honneth, op. cit. (nota 31), p. 155
} 
democracia moderna son la base del contubernio oscuro y la componenda inmoral: la política de pactos y compromisos, por ejemplo, es vista como la suplantación de la genuina voluntad popular. La siempre enrevesada esfera institucional de la democracia representativa desincentiva el interés colectivo por desentrañar los detalles confusos de la esfera política. Como remedio surge entonces el anhelo de simplificar el proceso decisorio y electoral, aunque esto signifique, en el fondo, el rechazo de la modernidad política, la impugnación del actual mundo complejo, el retorno a lo conocido, cercano y comprensible. En sociedades con una tradición autoritaria el regreso al caudillismo convencional es percibido como una vuelta a una constelación donde rigen los valores y las directivas simples de la infancia y la familia.

Pensadores afines a corrientes populistas y, sobre todo, al organicismo antiliberal se han sentido atraídos por la revalorización que realizó Carl Schmitt del poder político como una fuerza extraordinaria, primordial y casi sagrada, idea contrapuesta a la comprensión del poder como una forma altamente estructurada de dominación con sus rutinas de legalización y estabilización y con su propensión a generar normas burocráticas relativamente complicadas. La doctrina de Schmitt como simplificación del fenómeno del poder ha sido un teorema siempre bienvenido en periodos históricos cansados de sutilezas ${ }^{37}$. Para las corrientes asentadas en la tradición autoritaria, el decisionismo resulta ser la respuesta adecuada al detestable contractualismo liberal, porque el fundamento primero y último del orden político sería la decisión irracional y no las normas debatidas de modo discursivo y democrático. Schmitt estuvo en contra de pensar lo político como una actividad falible e incierta, porque en el fondo tenía añoranza por un orden social simple y basado en certidumbres inequívocas. Además: la argumentación discursiva permanente y la tolerancia pluralista no constituirían, según Schmitt, elementos genuinos de la democracia contemporánea de masas. Esta última estaría determinada por factores irracionales, "voluntaristas" y plebiscitarios: el pueblo tomaría sus decisiones según los criterios de simpatía y antipatía, de amistad y enemistad. Esto incluiría a menudo la identidad de gobernantes y gobernados ${ }^{38}$. En el fondo la doctrina de Schmitt propugnaba una concepción de lo político como un retorno definitivo a lo arcaico y primordial, una vuelta a lo elemental, sano y a veces irracional, que, de acuerdo a Schmitt, se diferenciaría radical y ventajosamente del ámbito moderno, corrompido por la incertidumbre liminar, la racionalidad instrumental y el juego de intereses ${ }^{39}$.

37 Cf. los estudios críticos: Jorge E. Dotti, Carl Schmitt en Argentina, Rosario: Homo sapiens 2000; Jorge E. Dotti / Julio Pinto, Carl Schmitt: su época y su pensamiento, Buenos Aires: Eudeba 2002; José Luis Villacañas / Román García, Walter Benjamin y Carl Schmitt. Soberanía y estado de excepción, en: DAIMON. REVISTA DE FILOSOFÍA (Murcia), № 13, julio-diciembre de 1996, pp. 14-60 (número monográfico dedicado al tema: "Carl Schmitt. Entre teología y mitología política"); Heinrich Meier, Carl Schmitt, Leo Strauss y el "concepto de lo político", Buenos: Aires: Katz 2008.

${ }_{38}$ Carl Schmitt, Die geistesgeschichtliche Lage des heutigen Parlamentarismus (La situación ideológico-histórica del parlamentarismo actual) [1923], Berlin: Duncker \& Humblot 1996, pp. $20-$ 36.

39 Cf. el instructivo ensayo de Thomas Blanke, Carl Schmitt - ein intellektueller Antiintellektueller (Carl Schmitt - un intelectual anti-intelectual), en: Thomas Jung / Stefan Müller-Doohm (comps.), Fliegende Fische. Eine Soziologie des Intellektuellen in 20 Porträts (Peces voladores. Una sociología del intelectual en 20 retratos), Frankfurt: Fischer 2009, pp. 250-268, aquí p. 254, 259. 
Ambos impulsos: el retorno al orden premoderno (que reduce la inseguridad) y el rechazo del complejo sistema institucional de cuño liberal-democrático (que evita el juego político en cuanto componenda inmoral de comerciantes y administradores), tienen una larga serie de ilustres antecedentes y propagandistas en varias tradiciones culturales. No sólo la propensión de JeanJacques Rousseau - uno de los autores favoritos de Carl Schmitt - hacia la democracia directa, sino también el actual renacimiento de formas autóctonas de hacer política en varias regiones latinoamericanas y en el ámbito islámico, coinciden en calificar el libre juego de intereses, las negociaciones políticas y el pluralismo ideológico como algo contrario a la genuina voluntad popular. Estas herencias culturales comparten con Schmitt la aversión a la heterogeneidad de todo tipo como si fuese una carencia o una equivocación del desarrollo histórico ${ }^{40}$. De aquí se llega rápidamente a impugnar la racionalidad de sistemas electorales "neoliberales" basados en el voto individual y secreto y a propagar la "necesidad" de regresar a la aclamación abierta y al voto colectivo público ${ }^{41}$.

En general la voz del pueblo se manifestaría clara y abiertamente por medio de plebiscitos y referéndums, es decir a través de métodos relativamente simples, en los cuales la población se expresa de acuerdo al binomio sí o no. Esto tendría la ventaja de una gran cercanía al pensamiento popular y a la voluntad auténtica del pueblo. Estas opciones decisorias son evidentemente fáciles de comprender y corresponden a la dicotomía básica "amigo / enemigo", que, como se sabe, ha sido y es parte integral de ideologías autoritarias. Carl Schmitt afirmó que el enemigo político no necesita ser "moralmente abyecto", ni "estéticamente feo". Tampoco es obligatoriamente un concurrente económico; se puede hacer negocios con él. Pero basta que sea el otro, el extraño en un sentido intenso y existencial, para que se convierta en el adversario ${ }^{42}$. La dicotomía "amigo / enemigo" ayuda entonces a expresar fácilmente la identificación del "pueblo" con el gobierno que propone esta disyuntiva plebiscitaria, y esta identificación contribuye, a su vez, a consolidar una democracia homogénea que expulsa sin grandes miramientos a los elementos heterogéneos ${ }^{43}$. En la praxis latinoamericana los sistemas populistas y sus defensores creen que este tipo de democracia directa es lo adecuado para eximirse de los molestos elementos liberales y pluralistas. Al devaluar todo rasgo discursivo-argumentativo, se prepara el terreno para percibir a los líderes carismáticos como fenómenos que no pueden ser comprendidos racionalmente, sino sólo experimentados existencialmente, lo que además sirve para exculpar de toda responsabilidad histórica a las tendencias autoritarias y populistas. El caudillo, según Martin

40 Ana Polack, Democracia, representación y ciudadanía en el pensamiento de Carl Schmitt, en: REFLEXIÓN POLÍTICA (Bucaramanga), vol. 13, No 26, diciembre de 2011, pp. 54-64, especialmente p. 55, 57. Similar ha sido la repulsión de la Teoría de la Dependencia con respecto a la denostada "heterogeneidad estructural".

41 lbid., p. 59 (tema favorecido por algunos sectores importantes de los regímenes populistas de la región andina).

42 Carl Schmitt, Der Begriff des Politischen (El concepto de lo político) [1932], Berlin: Duncker \& Humblot 2009, pp. 21-28.

$43 \quad$ Carl Schmitt, Der Begriff..., op. cit. (nota 42), pp. 20-24; Carl Schmitt, Die geistesgeschichtliche..., op. cit. (nota 38), pp. 12-26, 33-41. 
Heidegger y Carl Schmitt, personificaría una voluntad general de corte rousseauniano que estaría por encima de constituciones y leyes ${ }^{44}$.

Esta dicotomía política fundamental (amigo / enemigo) tiene una larga historia en la política latinoamericana en cuanto oposición binaria excluyente. Las famosas contraposiciones ideadas o propaladas por el peronismo argentino, patria / antipatria, nación / antinación, han tenido hasta hoy una considerable eficacia en la praxis política ${ }^{45}$. ¿Quién va a estar dispuesto a buscar o encontrar aspectos positivos en un fenómeno llamado antipatria o antinación? Algo similar sucede con el dualismo de sentimientos y fe, por un lado, y leyes e instituciones, por otro; los sentimientos son percibidos como algo noble y luminoso, mientras que las instituciones son vistas a menudo como la fuente de la injusticia y las trampas. Esto favorece la identificación fácil con aquellos fenómenos ideológicos y políticos definidos a priori como positivos, es decir: sacralizados por una autoridad política o religiosa. Es probable, sin embargo, que toda identificación fácil sea a la larga un obstáculo con respecto a un proceso intelectual que intenta comprender una temática compleja. El teorema de amigo / enemigo no sólo explica una realidad, sino que legitima un orden político y también justifica y da lustre argumentativo a una constelación preconstituida como tal.

Paradójicamente en la sencillez de la concepción de Schmitt y en su rechazo implícito de lo incierto reside su aceptación por intelectuales desorientados que buscan afanosamente el núcleo irreductible, el cimiento último de la vida política. Ellos suponen que el radicalismo de esta concepción contribuye a descubrir la presunta esencia de lo genuinamente político, radicalismo que ayudaría a desvelar la hipocresía que encubre la engorrosa democracia parlamentaria y pluralista. El poder es identificado con algo que no se puede definir claramente, pero que posee una enorme fuerza de atracción: el poder entorpece la serenidad del intelectual, pero produce una soif de l'infini difícilmente explicable y al mismo tiempo embriagadora - un fin en sí mismo -, que hace a un lado la preocupación, vista en tal caso como subalterna, de tener que definir para qué se quiere conquistar el poder. Es un decisionismo resuelto y firme, pero sin metas claras y, por supuesto, sin propósitos negociables. Como afirmó Volker Gerhardt en un texto muy meditado, este concepto nietzscheano de poder, sin contenido, exento de metas discernibles y sin tener la obligación de justificarse, es vacío y no tiene ninguna utilidad racional ${ }^{46}$. Las concepciones decisionistas de Carl Schmitt y autores afines tienden a enaltecer excesivamente la voluntad política del Estado, que sería cambiante e imprevisible, y que no debería limitarse a una razón mutilada por el discurso argumentativo ${ }^{47}$.

44 Carl Schmitt, Der Begriff..., ibid., pp. pp. 50-64; Reinhard Mehring, op. cit. (nota 20), p. 65.

Peter Waldmann, Der Peronismus 1943-1955 (El peronismo 1943-1955), Hamburgo: Hoffmann \& Campe 1974, pp. 77-104, 113-118, 131-152, 269-280; algunos aspectos muy interesantes en: Mariano Plotkin, Mañana es San Perón. Propaganda, rituales políticos y educación en el régimen peronista (1946-1955), Buenos Aires: Ariel 1993.

46 Volker Gerhardt, Macht und Metaphysik. Nietzsches Machtbegriff im Wandel der Interpretation (Poder y metafísica. El concepto nietzscheano de poder en el curso cambiante de la interpretación), en: Volker Gerhardt, Pathos und Distanz. Studien zur Philosophie Friedrich Nietzsches (Pasión y distancia. Estudios sobre la filosofía de Friedrich Nietzsche), Stuttgart: Reclam 1988, pp. 72-97, aquí p. 78.

47 Cf. tres excelentes textos que hacen alusión al decisionismo de Carl Schmitt, a sus antecedentes nietzscheanos y a la tendencia hacia el activismo por el activismo: Otfried Höffe, Demokratie im Zeitlater der Globalisierung (Democracia en la era de la globalización), Munich: 
Pese a las abiertas simpatías fascistas de Schmitt, su influencia no deja de crecer en círculos "progresistas" y populistas de América Latina: una popularidad tan dilatada como sorprendente. Se supone que Schmitt logró fundamentar teóricamente una imprescindible revalorización de la voluntad popular y del decisionismo que ahora estarían a la orden del día. Y a todo esto hay que añadir en América Latina la atracción positiva que irradia la violencia política - admitida por Karl Marx como uno de los grandes impulsos históricos - en cuanto la gran fuerza regeneradora de sociedades adormiladas por las corrientes "foráneas" del liberalismo y el pluralismo. Una pensadora muy influyente en el Nuevo Mundo, Chantal Mouffe, criticó con toda razón a los teóricos optimistas y hasta apologéticos de la globalización, que postulan un pluralismo aséptico, una confrontación dulcificada de intereses sociales y la desaparición de todo antinomia genuinamente política en un mundo signado aparentemente por la tolerancia liberal y la probabilidad de un consenso razonado ${ }^{48}$. Frente a esta visión "antipolítica", Mouffe, basada parcialmente en argumentos de Carl Schmitt, propugnó nuevamente una crítica radical del liberalismo, especialmente a sus fundamentos racionalistas e individualistas, que, de acuerdo a su concepción, imposibilitan el reconocimiento de identidades colectivas y el adecuado tratamiento de regímenes populistas y de sistemas sociales colectivistas ${ }^{49}$. Esta autora supone que los antagonismos (en la modalidad que ella llama "agonismos") no desaparecen jamás y que es indispensable un instrumento teórico fundamentado en el teorema de amigos / enemigos (como ella también los llama: "nosotros / ellos") para aprehender correctamente el campo de lo político.

Lo criticable en la teoría de Mouffe es la insistencia en explicar la dimensión actual de la política mediante oposiciones binarias excluyentes - como las que postuló Carl Schmitt - y la inclinación a diluir la vigencia de los derechos humanos y los procedimientos del Estado de derecho por medio del argumento, cómodo y peligroso, de que estos fenómenos representan características específicas de la cultura occidental, que por ello no son universalizables y no pueden y no deben ser impuestas a otros modelos civilizatorios en el planeta ${ }^{50}$. El efecto final de este enfoque es, en claro paralelismo con Carl Schmitt, la simplificación de una problemática compleja y la "comprensión" benevolente de todo tipo de régimen autoritario y populista.

En las últimas décadas el decisionismo se ha mimetizado exitosamente con la evolución de las ciencias sociales. No renuncia a su irracionalismo fundamental,

Beck 1999, p. 153, 302; Karl Löwith, Mein Leben in Deutschland vor und nach 1933 (Mi vida en Alemania antes y después de 1933), Stuttgart / Weimar: Metzler 2007, pp. 30-36, 42, 158; Reinhard Mehring, Politische Philosophie (Filosofía política), Leipzig: Reclam 2005, pp. 41-67.

${ }_{48}$ Chantal Mouffe, Über das Politische. Wider die kosmopolitische Illusion (Sobre lo político. Contra la ilusión cosmopolita), Frankfurt: Suhrkamp 2007, pp. 7-11, 170.

$49 \quad$ Ibid., pp. 17, 113-114, 165.

50 Ibid., pp. 164-165.- Cf. también: Chantal Mouffe, La paradoja democrática, Barcelona: Gedisa 2003; Chantal Mouffe (comp.), Deconstrucción y pragmatismo, Buenos Aires: Paidós 1998; Ernesto Laclau / Chantal Mouffe, Hegemonía y estrategia socialista. Hacia una radicalización de la democracia, Madrid: Siglo XXI 1987; Ernesto Laclau, La razón populista, Buenos Aires: FCE 2005; Daniel Gutiérrez Vera, Ernesto Laclau: el populismo y sus avatares, en: íCONOS (Quito), vol. 15, $N^{\circ} 40$, mayo de 2011, pp. 151-168. 
pero este último aparece como una manifestación legítima dentro del relativismo axiológico de nuestros días. Los teoremas decisionistas son considerados ahora como modelos científicos destinados al terreno de las competencias decisorias, y están basados en un enfoque neopositivista, que de modo sumario puede ser descrito como la imposibilidad de definir y comprender racionalmente la esfera de los valores. De acuerdo a este enfoque, hay que diferenciar entre las obligaciones del político - que se hallan en la esfera de lo axiológico -, por un lado, y las tareas de los expertos, que corresponden al acopio y sistematización de informaciones, por otro. La provisión ordenada de datos corresponde al campo de la racionalidad instrumental. En cambio el político tiene el deber permanente de realizar actos electivos, operación que en última instancia no puede ser argumentada racionalmente. A causa de la enorme complejidad del mundo actual, esta actividad del político, basada en valores, no puede estar fundamentada discursivamente; sus decisiones no son habitualmente aceptadas por todos. Desde este punto de vista la racionalidad que postulan los humanistas resulta algo anticuado que sólo se podría aplicar en ámbitos muy delimitados, como los sectores inferiores de la administración estatal ${ }^{51}$.

Todos realizamos una reducción de complejidad para comprender el mundo y a nosotros mismos, pero existen notables diferencias de calidad - y de consecuencias prácticas - debidas a los distintos métodos empleados. En el plano socio-político, por ejemplo, se puede aminorar la complejidad mediante acciones e instructivos ideológicos decretados desde arriba y obedecidos sin mucha resistencia por las instancias y las clases subalternas. Todo esto se puede llevar a cabo siguiendo escrupulosamente lineamientos administrativos aceptados en su momento, de modo que aquí se puede hablar con propiedad de una legitimidad sostenida y justificada mediante procedimientos legales. Esto también se da en la doctrina y la praxis tecnocráticas. No es necesario mencionar cuáles derivaciones práctico-políticas puede englobar este modelo.

Pero también se puede limitar la complejidad por medio de una discusión abierta entre los participantes e interesados, en la cual las etapas y modalidades de la reducción son determinadas de acuerdo a argumentos explicitados por el debate y controlados por la acción discursiva. Estos mecanismos pueden ayudarnos a evitar las arbitrariedades y los errores que posee todo proceso de simplificación de complejidades, y pueden ser mejores que los métodos autoritarios y convencionales que vienen dictados desde arriba, puesto que este sistema no prescribe una elección imperativa entre sólo dos valores, ambos desprovistos de elementos racionales, sino un ejercicio democrático de debate entre varias opciones, que a lo largo de la discusión se van decantando como posibilidades de prácticas más o menos razonables, dentro de un contexto signado por la falibilidad, pero también por la probabilidad de correcciones parciales. Si el debate es suficientemente abierto, tolerante y flexible, las cualidades de lo racional y lo democrático tienden a coincidir, dentro de un juego concebido desde un comienzo como perfectible, pese a toda la precariedad de los asuntos

51 Cf. Niklas Luhmann, Legitimation durch Verfahren (Legitimidad mediante procedimientos) [1969], Frankfurt: Suhrkamp 2001; Alex Demirovic (comp.), Komplexität und Emanzipation. Kritische Gesellschaftstheorie und die Herausforderung der Systemtheorie Niklas Luhmanns (Complejidad y emancipación. La teoría crítica de la sociedad y el desafío de la Teoría de Sistemas de Niklas Luhmann), Münster: Westfälisches Dampfboot 2001. 
públicos, y sin el dramatismo que está asociado históricamente al decisionismo en la realidad política.

\section{Conclusiones provisionales}

La base última de la problemática aquí tratada reside en una paradoja histórica: el éxito y la facultad de atracción de la modernidad occidental, que es ambicionada y detestada simultáneamente. Casi todas las corrientes indigenistas, indianistas, nacionalistas, teluristas y hasta socialistas combinan un rechazo radical de las esferas política, ética y cultural de la modernidad occidental con una aceptación, a menudo entusiasta, de sus adelantos tecnológicos. En una buena parte del Tercer Mundo se cuestionan enfáticamente los logros del modelo civilizatorio occidental, sobre todo en la perspectiva político-institucional, pero al mismo tiempo se quiere alcanzar rápidamente los adelantos técnicos y económicos que han surgido de ese mismo ámbito. El resultado es una ambivalencia básica y traumática frente a la modernidad occidental, una constelación signada por la propensión a la imitación y el anhelo de producir un nuevo paradigma civilizatorio original. A más tardar en la segunda mitad del siglo XIX los factores de proveniencia occidental diluyeron la vigencia de los valores ancestrales de orientación y conducta y llevaron a la pregunta por la identidad nacional. En el Tercer Mundo todas las identidades basadas en la tradición entraron en crisis frente a un modelo civilizatorio exitoso, basado en la ciencia y la tecnología e inspirado por normativas universalistas en casi todos los campos.

En este contexto hay que buscar el derecho y la fuerza de las teorías antioccidentalistas, como las englobadas bajo los rubros de la subalternidad y la descolonización. Pero al mismo tiempo estas corrientes han renunciado deliberadamente a la dimensión crítica y representan, por consiguiente, un serio obstáculo para la comprensión de muchos problemas actuales, como la persistencia del arcaísmo cultural en el seno de procesos de globalización y el surgimiento de la crisis ecológica en medio del tan deseado progreso tecnológico. En muchos países del Tercer Mundo la crítica general de la legitimidad histórica de un modelo social basado en el Estado de derecho y en la vigencia de los derechos humanos contribuye a reflotar antiguas tradiciones autoritarias, que ahora, con lustre académico y vocabulario progresista, retornan para ser consideradas como los fundamentos autóctonos de un régimen que se ha liberado del colonialismo cultural.

Estas teorías dejan de lado la posibilidad de que el renacimiento del pasado mítico contenga mayoritariamente elementos de una interesada "invención de la tradición" y la probabilidad de que la memoria arcaica encierre también factores de una herencia cultural fuertemente autoritaria y adversa a toda forma moderna de democracia, al espíritu crítico, a la investigación científica y a la emancipación femenina. No es casualidad que en América Latina y particularmente en el área andina no se hayan publicado investigaciones sobre la estructura familiar del mundo indígena, ni tampoco en torno a las relaciones patriarcales y verticalistas que prevalecen en las comunidades campesinas; la insatisfacción crónica de las mujeres de los estratos sin acceso a una buena educación fomenta indirecta pero seguramente una atmósfera generalizada de autoritarismo colectivista. Estos son temas que no despiertan el interés de aquellos intelectuales consagrados a 
admirar los logros civilizatorios de un pasado embellecido indebidamente por esfuerzos teóricos de considerable envergadura. 